\title{
Quality Assessment of Milling Pavement Surface Using 3D Line Laser Technology
}

\author{
Bing Hui, Mu Guo $\mathbb{D}$, and Xiaofang Liu \\ School of Highway, Chang'an University, Middle Section of Nan Erhuan Road, Xi'an City, Shaanxi Province, China \\ Correspondence should be addressed to Mu Guo; guomu.zest@foxmail.com
}

Received 29 March 2018; Revised 28 June 2018; Accepted 15 July 2018; Published 8 August 2018

Academic Editor: Guiyun Tian

Copyright @ 2018 Bing Hui et al. This is an open access article distributed under the Creative Commons Attribution License, which permits unrestricted use, distribution, and reproduction in any medium, provided the original work is properly cited.

\begin{abstract}
To ensure that a regular milled surface texture provides good bonding without residual distress, a new specification of milling surface assessment has been established for quantitatively evaluating the milled surface quality. This research explores the possibility of using three-dimensional (3D) laser scanning technology to develop an algorithm to obtain a milled surface model that can measure evaluating indicators, milling depth and texture depth, and identify poorly milled areas. A case study was conducted by using a laser scanning vehicular system to collect 3D continuous pavement transverse profiles data in a $500 \mathrm{~m}$ long segment of Highway S107. The results show that the proposed method is very promising and can measure the milling depth and texture depth to effectively and quantitatively differentiate between good- (milling depth between $47 \mathrm{~mm}$ and $53 \mathrm{~mm}$ and texture depth exceeding $2 \mathrm{~mm}$ ) and poor-quality work. Moreover, the poorly milled areas such as those with residual distress and unmilled areas that will lead to premature failure can also be identified using the proposed method. The proposed method can effectively support remilling work and ensure the quality of the overlay pavement.
\end{abstract}

\section{Introduction}

Currently, milling for rehabilitation of asphalt concrete pavement in conjunction with an overlay is the primary maintenance method, as stated in the "Technical Specification of Maintenance for Highway" in China [1]. This method is applicable to treatment of surface damage such as cracks, potholes, raveling, poor roughness, and insufficient skid resistance. The operation is to cut the poor pavement surface using a large automatic milling machine and replace it with a new asphalt mixture of the same thickness [2]. The milling drum has approximately $100-700$ teeth, and various types of milling drums are selected according to the required milling depth and texture depth, and the milling depth and overlay thickness are determined by the characteristics and severity of the pavement damage [3].

Many factors may cause the milling depth excessive and inadequate, including pavement distress like rutting and subsidence, speed fluctuations of milling machine, and rotation rate of the drum. When the milling depth exceeds the expected threshold, it will affect the overall stability and structural strength, resulting in various forms of distress such as cracking, potholes, and rutting rapidly appearing in the overlay pavement [4]. When the milling depth is insufficient, it is difficult to create a uniform texture in the milled surface, causing uneven distribution of the adhesive layer (sprayed emulsified asphalt) and poor bonding between the overlay and milled surface. Consequently, some forms of distress emerge over a certain time of service, including raveling, shoving, and rutting [5-8]. The thinner the design overlay, the more significant are the impacts of the milling depth and control of texture on the overlay service life [9]. Therefore, accurate milling depth and texture control are the keys to achieving the required service life of the overlay surface and cost-effective maintenance methods.

Measurement of the milling depth and texture is performed by skilled personnel using a $3 \mathrm{~m}$ ruler with a $100 \mathrm{~m}$ unit for random point detection [10]. Such measurement is influenced by a long distance of milling, a wide area, and a small deviation index, which inevitably reduce the accuracy and efficiency of artificial sampling in the field. It is difficult to accurately identify substandard areas and their specific positions and provide a scientific assessment of the milling quality. Rapid, milling depth and texture assessment, 
which is comprehensive and accurate, is an important basis for judging the quality of the milling and ensuring the design life of the overlay surface.

For such assessments, researchers have introduced the use of emerging 3D laser technology. This technology can create road surface laser data across an entire lane, measuring with high data precision, high data density, and measuring speed, and has been applied to measure rutting and cracks, even pavement quality assessment of smoothness and macrotexture [11-15]. Hao et al.[16] used data interpolation and a surface fitting method to process a 10 -point profile of $3 \mathrm{D}$ laser grooving data and calculated the depth to evaluate grooving abrasion status; the results were found to correlate well with the results of the sand patch method. Lee et al. [17] used 3D laser equipment to collect indoor grooving model data and adopted section grooving depth and groove spacing indicators to verify the feasibility of using a 3D laser for grooving measurement. Li et al. [18] and Kelvin et al. (2012) separately obtained site grooving data from cement concrete pavement using 3D laser technology; according to the indicators of depth, width, and spacing to evaluate the grooving uniformity, the results showed that 3D laser technology can achieve comprehensive, accurate assessment of grooving texture. Focusing on milled pavement construction, Tsai et al.[15, 19] collected surface texture data of micromilling of an asphalt pavement based on Georgia Tech's sensing vehicle and proposed the ridgeto-valley-depth (RVD) to evaluate milling repeatability; using this approach, they determined the locations of problem areas. The aforementioned research verified the feasibility of using 3D laser technology for pavement texture assessment; however, no assessment of roughness and flatness of milled pavement was provided, these studies failed to identify the areas and locations of substandard milling, the results did not support cause analysis of substandard work, and the conclusions of the studies lacked guiding significance for construction.

To address the shortcomings of the existing research for determining the locations of substandard milled area, a vehicular 3D laser detection system developed by Chang'an University was used to collect field asphalt milled surface texture data, a 3D model of the milled surface was constructed, and a texture depth and milling depth was proposed to analyze and evaluate the milling quality. The research results can serve as a basis for construction monitoring and quality assessment of milling operations, providing guidance for optimization of repairs of a milled surface, and provide reference for setting construction operation parameters.

This paper is organized as follows. This section briefly reviews the existing methods for evaluating milling data and identifies the need for an alternative means to costeffectively evaluate milling data. The second section briefly introduces the $3 \mathrm{D}$ continuous pavement profile data. A proposed method of evaluating milling texture is presented in the third section, followed by presentation of a case study conducted on a highway used to evaluate the performance method. The fourth section presents the results of the field tests. Finally, conclusions and recommendations for future research are discussed.

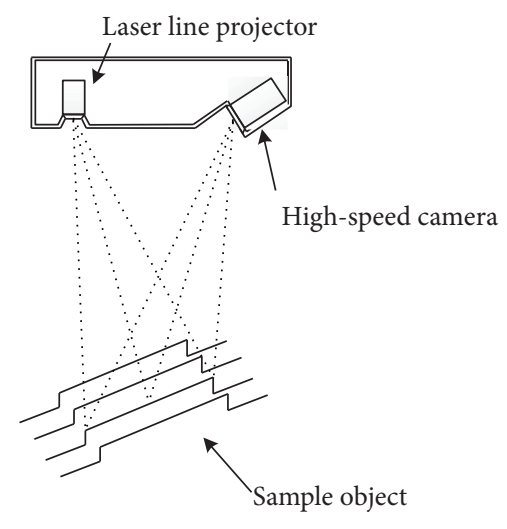

FIgURE 1: Triangulation principle of 3D laser detection.

\section{Acquisition of $3 D$ Continuous Transverse Profile Data}

This section briefly presents the principles of the $3 \mathrm{D}$ laser detection and the design of the laser scanning vehicular system that was used in this study. The 3D laser technology, which is based on the laser triangulation principle, was used to collect $3 \mathrm{D}$ continuous pavement transverse profile data. The laser line projector directs a continuous laser line onto the pavement, and the reflected laser line creates height information of the pavement surface. A high-speed camera captures the reflected laser line in subpixel images, as shown in Figure 1. Next, a subpixel peak measure algorithm is used to determine the location of the reflected laser subpixel to serve in 3D reconstruction of the pavement surface.

The laser scanning vehicular system developed by Chang'an University is contained in a sports utility vehicle (SUV) that is equipped with two laser scanning units, a vertical accelerometer and a high-resolution distance measurement instrument (DMI), as shown in Figure 2. The laser scanning units are mounted beneath a metal brace on the back of the SUV to acquire 3D continuous transverse profile data. The vertical accelerometer is mounted under the vehicle to record the vertical displacement to synchronously correct the profile data output obtained by the laser scanning units. The DMI is mounted on the right rear wheel and controls the interval between two consecutive transverse profiles.

Two laser scanning units (Model Gocator-2380) are used to collect 3D continuous transverse pavement profiles. These units are approximately $1.8 \mathrm{~m}$ above the ground. Each unit collects $1.2 \mathrm{~m}$ wide transverse profiles with over $20003 \mathrm{D}$ laser points and cover a $2.4 \mathrm{~m}$ transverse field-of-view. When the vehicle speed is no greater than $40 \mathrm{~km} / \mathrm{h}$, the laser scanning unit controlled by the DMI can collect data at an interval of $2 \mathrm{~mm}$ in the travel direction and with a scan frequency of 4500 profiles per second. To ensure that these units can measure the milling texture, the two laser scanning units provide a $0.55 \mathrm{~mm}$ resolution in the transverse direction and at least a $0.5 \mathrm{~mm}$ resolution in the vertical direction after setting the device parameters.

The scanned pavement data from the 3D laser detection is saved as a point matrix; an example of the scanning results 


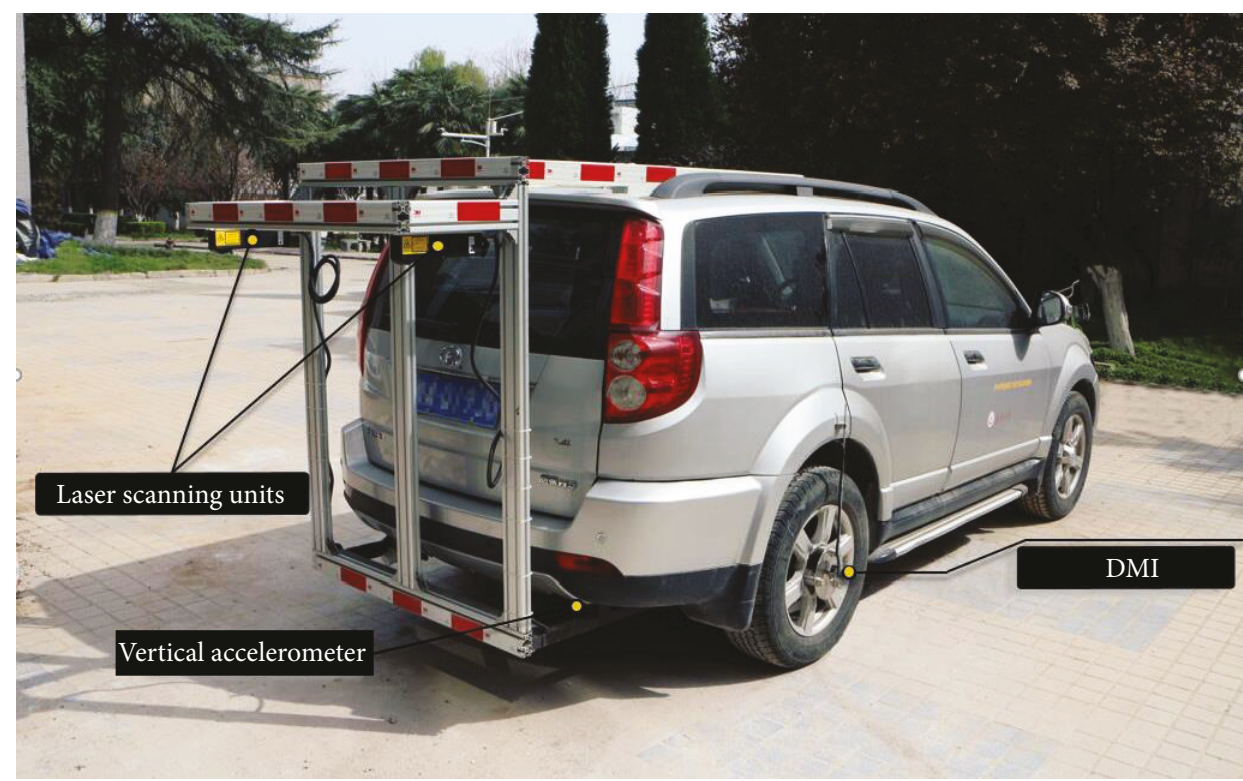

FIGURE 2: Configuration of the laser scanning vehicular system (LSVS).

TABLE 1: Summary of original milling data using laser scanning vehicular system.

\begin{tabular}{ccccccccccccc}
\hline & & \multicolumn{1}{c}{ Transverse profile $(\mathrm{mm})$} \\
& Height $(\mathrm{mm})$ & -299.3 & -298.8 & $\ldots$ & -198.9 & -198.4 & -197.9 & -197.4 & $\ldots$ & 299.5 & 300 \\
\hline & 0.4 & -50.72 & -50.60 & $\ldots$ & -50.38 & -50.28 & -50.18 & -50.08 & $\ldots$ & -40.91 & -40.83 \\
& 2.4 & -50.31 & -50.18 & $\ldots$ & -40.94 & -40.83 & -40.73 & -40.64 & $\ldots$ & -40.49 & -40.42 \\
& $\ldots$ & $\ldots$ & $\ldots$ & $\ldots$ & $\ldots$ & $\ldots$ & $\ldots$ & $\ldots$ & $\ldots$ & $\ldots$ & $\ldots$ \\
Longitudinal profile $(\mathrm{mm})$ & 160.4 & -50.30 & -50.19 & $\ldots$ & -40.98 & -40.89 & -40.81 & -40.73 & $\ldots$ & -40.61 & -40.56 \\
& 162.4 & -50.36 & -50.25 & $\ldots$ & -50.05 & -40.96 & -40.88 & -40.81 & $\ldots$ & -40.69 & -40.64 \\
& 164.4 & -50.25 & -50.20 & $\ldots$ & -50.11 & -50.07 & -50.03 & -40.99 & $\ldots$ & -40.92 & -40.89 \\
& 166.4 & -50.04 & -50.03 & $\ldots$ & -50.02 & -50.02 & -50.01 & -50.01 & $\ldots$ & -40.99 & -40.99 \\
& $\ldots$ & $\ldots$ & $\ldots$ & $\ldots$ & $\ldots$ & $\ldots$ & $\ldots$ & $\ldots$ & $\ldots$ & $\ldots$ & $\ldots$ \\
& 998.4 & -40.50 & -40.60 & $\ldots$ & -40.77 & -40.85 & -40.92 & -40.99 & $\ldots$ & -50.12 & -50.18 \\
& 999.4 & -50.15 & -50.25 & $\ldots$ & -50.44 & -50.52 & -50.59 & -50.65 & $\ldots$ & -50.75 & -50.78 \\
\hline
\end{tabular}

is shown in Table 1. The first line of the matrix represents the $3 \mathrm{D}$ laser point locations in the transverse profile; the left and right endpoints are at $-299.3 \mathrm{~mm}$ and $300.0 \mathrm{~mm}$, respectively. The total length is approximately $600 \mathrm{~mm}$, and the transverse resolution is approximately $0.5 \mathrm{~mm}$. The first column of the matrix represents the $3 \mathrm{D}$ laser point locations in the longitudinal profile. The scanning interval is $2 \mathrm{~mm}$ in the travel direction, and the total length in the longitudinal profile is approximately $1000 \mathrm{~mm}$, ranging from $0.4 \mathrm{~mm}$ to $999.4 \mathrm{~mm}$. The remaining data represent the elevation coordinates of the corresponding $x$ and $y$ points.

\section{Method for Evaluation of Milled Surface}

3.1. Preprocessing of Transverse Profile Data. Considering the systematic error of the laser scanning unit and the macrotexture of the asphalt pavement, the height curves of the original 3D laser transverse profile contain some noise and macrotexture characteristics. To highlight the milled texture of the asphalt pavement, a locally weighted scatterplot filtering algorithm was used to process the laser transverse profile curves with MATLAB software. The transverse profile curve filtering with least squares and polynomial fitting was used to replace the original data. Figure 3 shows an example of the transverse profile curve filtering results when the width of the filtering window is set to 0.5 . The preliminary results of the curve filtering with 3D laser measurement demonstrate that the locally weighted scatterplot filtering algorithm can remove noise and unimportant texture characteristics; thus, this method is very promising for processing the transverse profile curve to improve the accuracy of the milled surface assessment.

3.2. Model of Milled Surface. Based on the milling texture data smoothed using the locally weighted scatterplot filtering algorithm, the $3 \mathrm{D}$ milling surface model is constructed using interpolation processing in MATLAB software. An example 


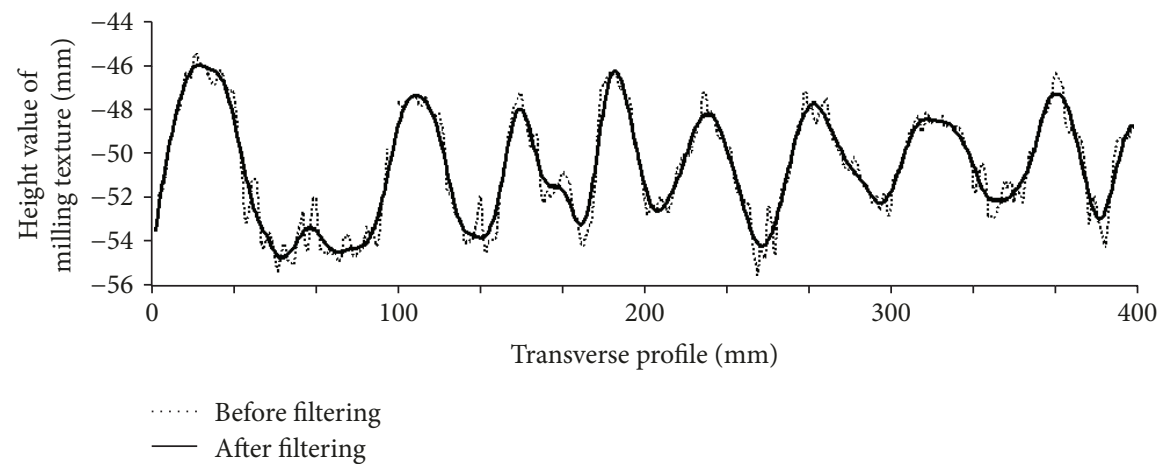

FIGURE 3: Filtering of the transverse profile data.

of a $600 \mathrm{~mm} \times 1000 \mathrm{~mm}$ milled surface texture model is shown in Figure 4; both the transverse and longitudinal resolutions of the model are equal to $0.5 \mathrm{~mm}$. Figure 4 shows the milled texture of the model surface and its symmetrical distribution. The substandard milling area in the center of model, which might be attributed to residual distress on milled surface (such as rutting and subsidence of subgrade or loss of aggregates via the fatigue of the asphalt bonder), is clearly captured by $3 \mathrm{D}$ laser detection. The preliminary results of the constructed milling model show that the locations and areas of poor milling can be identified using the laser milling data.

3.3. Calculation of Milling Indicators. Based on the field milling texture and the 3D model of the milled texture, the large shape differences found between milling valleys are caused by a variety of complex reasons attributed to the asphalt pavement. These conditions promote the low reproducibility of the roughness obtained from artificial sampling. Thus, the result is unreliable for evaluation of the milling surface. Tsai et al. investigated the measuring of milled textures using $3 \mathrm{D}$ laser detection and assessed the possibility of using ridge-to-valley-depths in $100 \mathrm{~mm}$ transverse profiles to evaluate the texture uniformity [15]. However, their method cannot fully utilize high-density data, and the final indicators are easily influenced by systematic error of the laser scanning unit.

In this paper, the milling depth and texture depth of milling valley units are proposed to evaluate the depth and roughness of the milling operation, respectively. The milling depth is indicated by the depth of milling machine cut into the asphalt pavement in the milling valley units. The texture depth is indicated by the maximum depth of the texture in the milling valley unit. The milling depth and texture depth of the milling valley are calculated as follows:

(1) Partition a $2400 \mathrm{~mm} \times 1000 \mathrm{~mm}$ scanning area into four blocks (blocks 1, 2, 3, and 4) along the transverse profile and construct a milling surface model for each part. Next, divide the milling surface model into several $600 \mathrm{~mm} \times 50 \mathrm{~mm}$ rectangular sections (sections $1,2, \ldots, n$ ) along the longitudinal direction and capture the midline curve of the laser transverse profile as the representative curve, as shown in

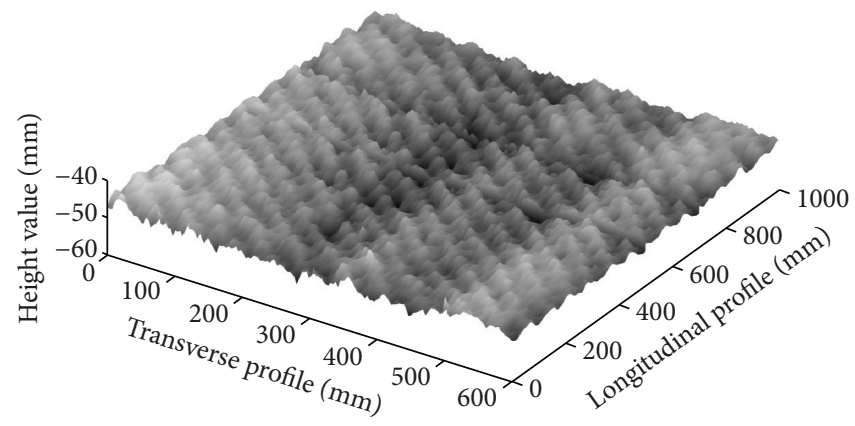

FIGURE 4: An example of 3D reconstructed model of milling surface.

Figure 5, to describe the milling condition and texture conditions of each section.

(2) With the curve peak extraction algorithm in MATLAB software, determine the peak points $\left(x_{i}, y_{i}\right)$ and trough points $\left(x_{j}, y_{j}\right)$ of the milling valley during 1.5 times the milling cutter spacing range from the representative curve, as shown in Figure 5. Next, partition the representative curve into several milling valley units (units $1,2, \ldots, m$ ) with peak points of the milling valley.

(3) Figure 6 illustrates the milling depth and texture depth of milling valley unit data used to calculate the milling depth $h_{i}$ of milling valley number $i$ using the formula

$$
h_{i}=\frac{1}{2}\left[\frac{\left(y_{i}+y_{j}\right)+\left(y_{i+1}-y_{i}\right) \times\left(x_{i}-x_{j}\right)}{\left(x_{j+1}-x_{j}\right)}\right] \text {, }
$$

and the texture depth $d_{i}$ of milling valley number $i$

$$
d_{i}=\frac{y_{j}+\left(y_{i+1}-y_{i}\right) \times\left(x_{i}-x_{j}\right)}{\left(x_{j+1}-x_{j}\right)}
$$

(4) According to data accuracy of 3D laser detection and Technology Specifications for Design and Construction of Ultra-Thin Friction Course (DB 21/T 1995-2012) [10], substandard milling areas can be characterized according to the design milling depth 


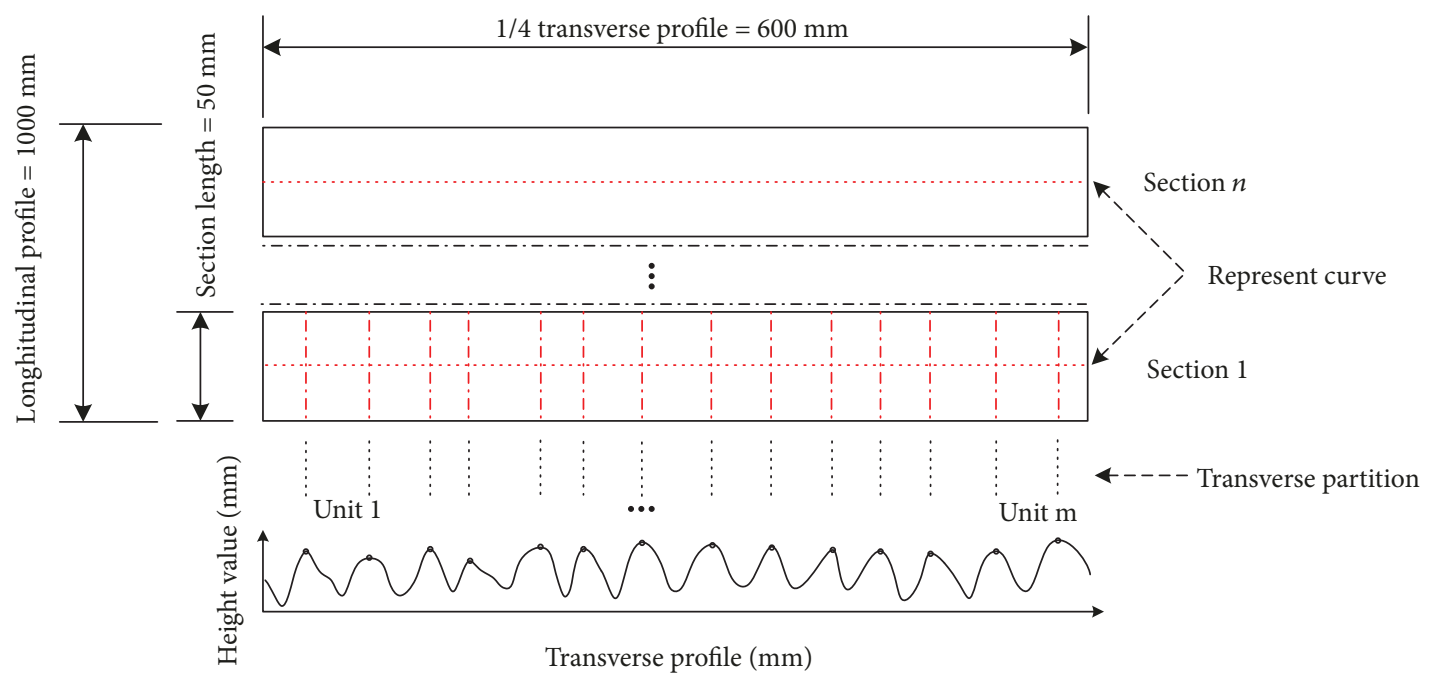

Figure 5: Divided sections and partition units from the model.

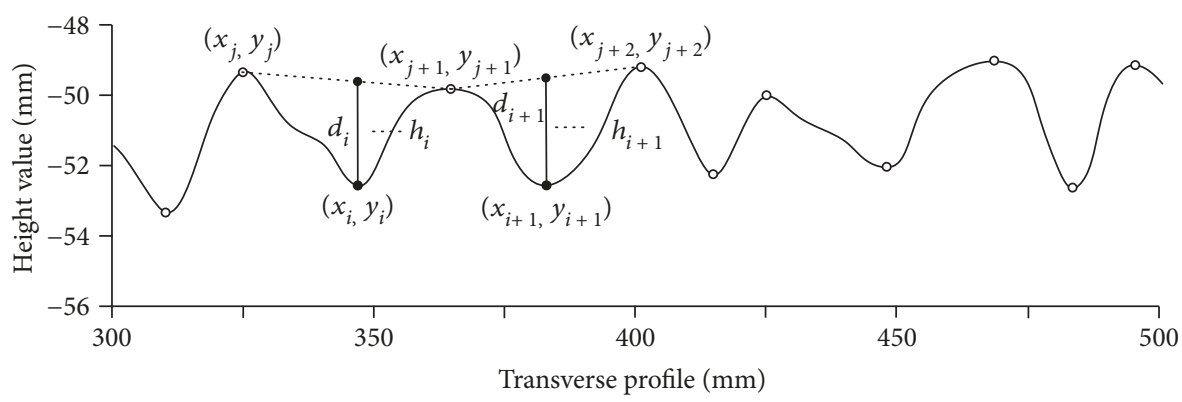

Figure 6: Milling depth and texture depth in the transverse profile.

and the theoretical texture depth of the corresponding milling cutter. The substandard milling areas are those where the milling depth difference exceeds $5 \%$ (ceiling to millimeter) of the design milling depth or the texture depth is less than $2 \mathrm{~mm}$. Considering the feasibility of remilling substandard areas, the areas of substandard milling also should be larger than $5000 \mathrm{~mm}^{2}$. Thus, the total area and nonacceptability of substandard milling in each $600 \mathrm{~mm} \times 1000 \mathrm{~mm}$ block are calculated.

\section{Case Study}

4.1. Field Sites. Field tests were conducted on a section of Highway S107 with a low longitudinal slope and straight asphalt pavement near Xi'an. Figure 7(a) shows the HD2000 super milling machine (which has a milling cutter spacing of $40 \mathrm{~mm}$ ) used for this operation. The milled pavement is shown in Figure 7(b). The asphalt pavement's upper layer is AC-13; it was milled to a depth of $50 \mathrm{~mm}$ to repair rutting and cracking of the pavement surface. The field test is designed to evaluate the roughness and texture of the milling surface and the feasibility of operating the laser scanning vehicular system at common traveling speeds.
With a vehicle speed of $45 \mathrm{~km} / \mathrm{h}$, the system acquires more than 5 million 3D data points from 2400 widths and $1000 \mathrm{~mm}$ long milling areas with substandard milling to describe the roughness and texture of the pavement surface in detail, as shown in Figure 8. Figure 8(a) shows the milling depth of the pavement, and an image of the measuring area is shown in Figure 8(b). A substandard milling area is marked on the image (Figure 8(b)); there, a loss of aggregate occurred, and the roughness is poor.

4.2. Test Results and Analysis. Figure 9 shows a 3D milling model of a block and an example of scatter plots of three sections of milling depths and texture depths. Twenty $50 \mathrm{~mm}$ long longitudinal sections with 13 milling units in block 1 were considered. The dotted line in the plot represents the critical access line of substandard milling in this operation: $2 \mathrm{~mm}$ for the texture depth and $-47 \mathrm{~mm}$ and $-53 \mathrm{~mm}$ for the milling depths.

The preliminary results of the texture depth and the milling depth of each block, as shown in Figure 9, demonstrate that the proposed method can accurately identify the location of the substandard area of milling and can calculate the proportion of the substandard area within the entire milled area. In section number 3 , the milling depths of units 6,7 , and 13 exceed $-47 \mathrm{~mm}$, and the 


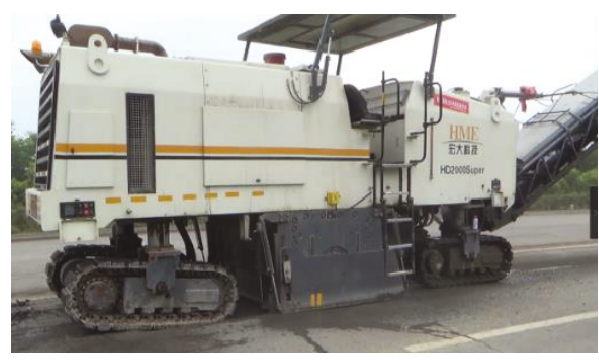

(a)

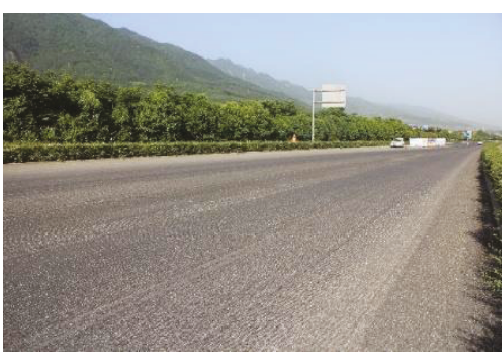

(b)

FIGURE 7: Milling operation on test field: (a) milling machine in the field and (b) milling surface in the field.

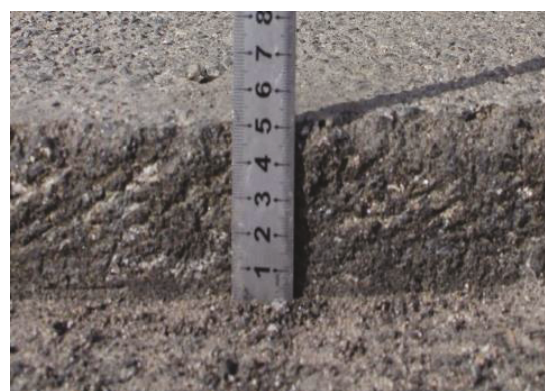

(a)

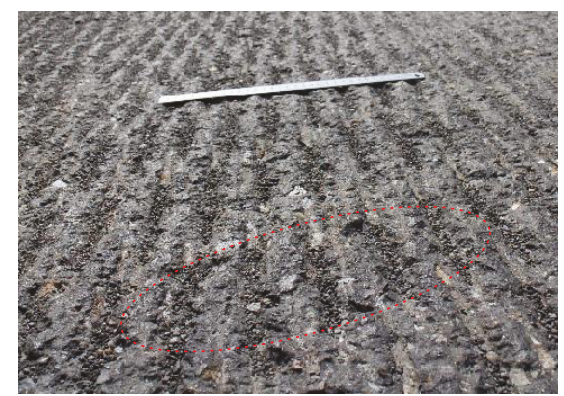

(b)

FIgURE 8: Milled pavement surface in the field: (a) milling depth after operation and (b) milling texture in the field.
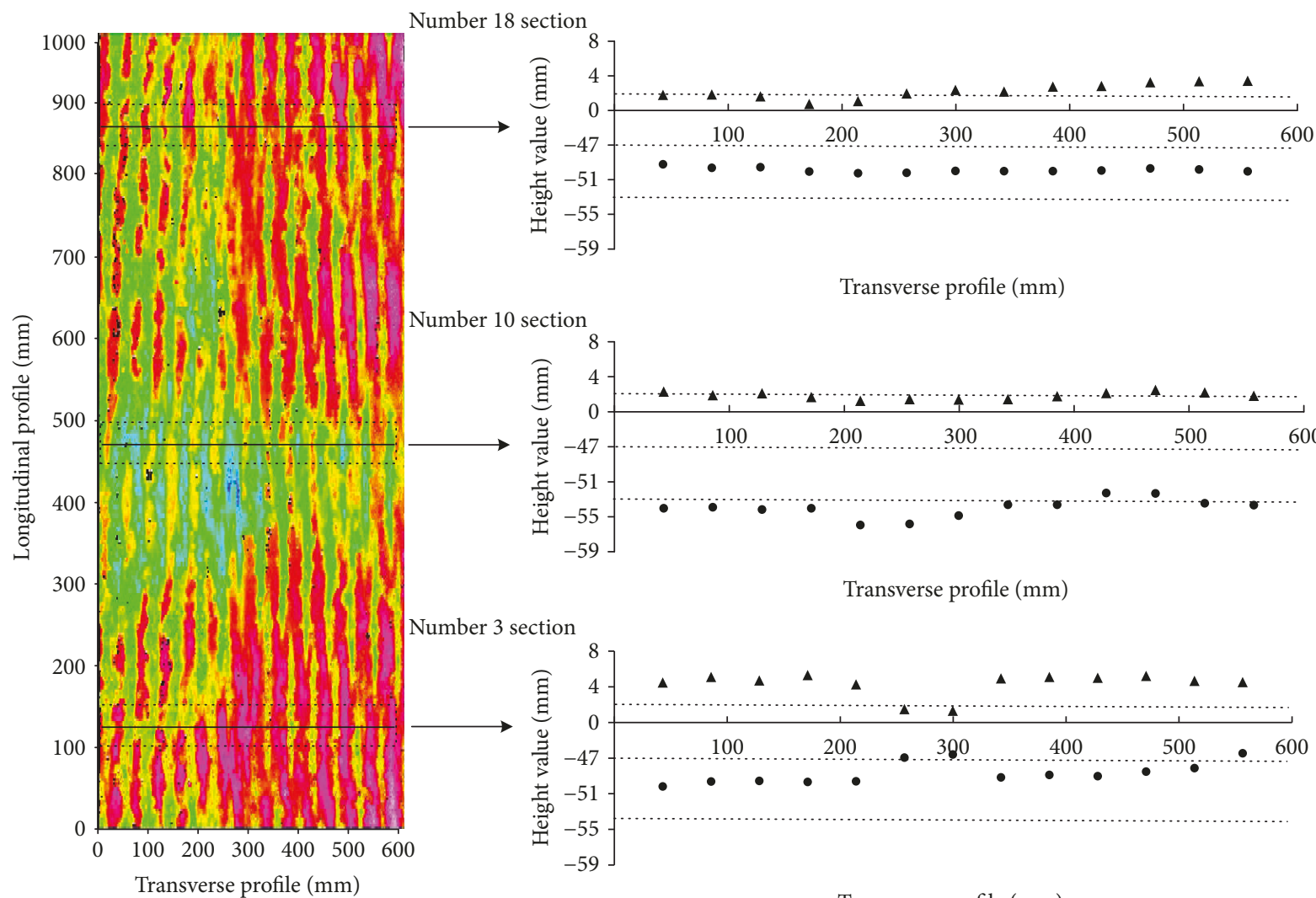

Transverse profile $(\mathrm{mm})$

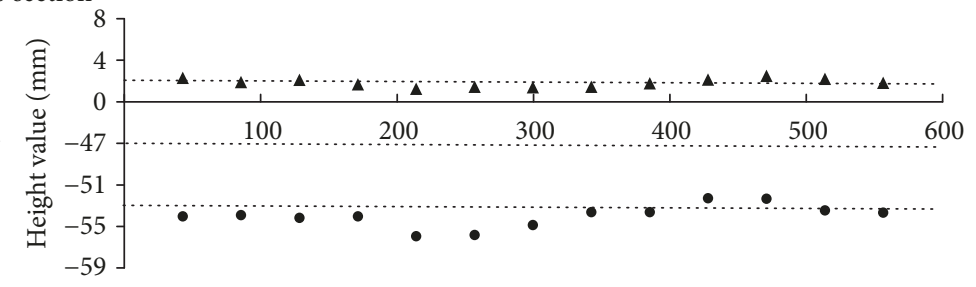

Transverse profile (mm)

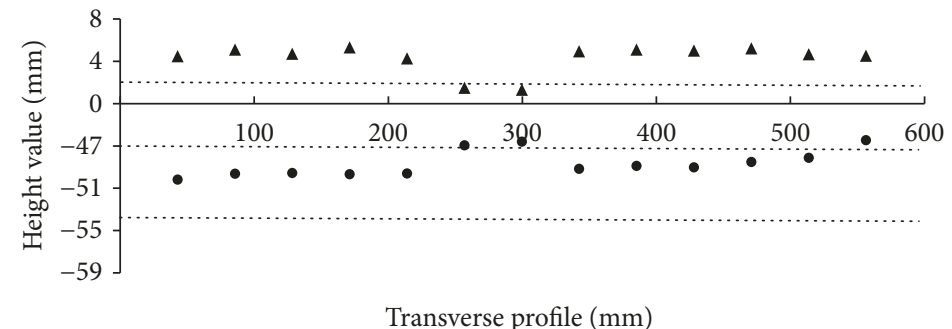

- Milling depth

- Texture depth

FIgURE 9: Example of texture depth and milling depth of block. 
TABLE 2: Location, area, and nonacceptability of blocks.

\begin{tabular}{lccccc}
\hline Sample ID & $\begin{array}{c}\text { Starting coordinates } \\
(\mathrm{mm})\end{array}$ & $\begin{array}{c}\text { Terminal coordinates } \\
(\mathrm{mm})\end{array}$ & $\begin{array}{c}\text { Cumulative width } \\
(\mathrm{mm})\end{array}$ & $\begin{array}{c}\text { Substandard area } \\
\left(\mathrm{mm}^{2}\right)\end{array}$ & $\begin{array}{c}\text { Substandard percentage } \\
(\%)\end{array}$ \\
\hline 1 & 501 & 587 & 86 & 4300 & $14.3 \%$ \\
3 & 235 & 322 & 128 & 6400 & $21.3 \%$ \\
7 & 541 & 582 & 264 & & $44.0 \%$ \\
8 & 19 & 283 & 271 & 13,200 & $45.2 \%$ \\
9 & 16 & 287 & 269 & 13,550 & $44.8 \%$ \\
10 & 22 & 291 & 505 & 13,450 & $84.2 \%$ \\
& 12 & 407 & 151 & 25,250 & $25.2 \%$ \\
13 & 479 & 589 & 171 & 7550 & $28.5 \%$ \\
14 & 435 & 586 & 250 & 8550 & $41.7 \%$ \\
20 & 426 & 597 & 156 & 12,500 & $26.0 \%$ \\
\hline
\end{tabular}

texture depths in units 6 and 7 are less than $2 \mathrm{~mm}$. In section number 10, all the milling depths, except those in units 10 and 11 , are less than $-53 \mathrm{~mm}$. In section number 18 , the texture depths in units 1 to 6 are less than $2 \mathrm{~mm}$. This situation may have been caused by the poor toughness of the original pavement; as a result, the milling quality is poor, leading to the loss of aggregate and uneven milling surface.

After integration of the substandard milling units, the substandard milling, as shown in Table 2, consists of 6 substandard areas in sections 1, 3, 7-10,13,14, 18, and 20; the total area is $112,550 \mathrm{~mm}^{2}$ and accounts for $18.7 \%$ of the block 1,which area is $600,000 \mathrm{~mm}^{2}$. The largest substandard milled area is $65,450 \mathrm{~mm}^{2}$; this area must be remilled by a milling machine to ensure the roughness of the surface.

Figure 10 shows 3 milling blocks in different locations of the milling operation, revealing that the distribution of substandard milling is different in each block. The substandard milling area in block 2 is in the central region from $250 \mathrm{~mm}$ to $450 \mathrm{~mm}$ of the transverse profile; the milling depth is less than the design range. This defect may have occurred because the rutting still exists on the milled surface, and the toughness is poor in the areas. The substandard milling areas in block 3 are in the region from $200 \mathrm{~mm}$ to $500 \mathrm{~mm}$ of the longitudinal profile; the milling depth is greater than the design range. This defect may be caused by the driving speed of milling machine being higher than usual, resulting in incomplete milling by the cutters. The substandard milling in block 3 is distributed across most of the blocks except in the region from $500 \mathrm{~mm}$ to $700 \mathrm{~mm}$ of the longitudinal profile; the milling and texture depths are less than the design ranges. This defect may have occurred because of subgrade subsidence, and the design milling depth was not adequate to repair this distress.

Table 3 lists the results of the milling quality assessment of 4 blocks. The results demonstrate that the number, area, and percentage of substandard milling areas can be determined using the proposed method via 3D laser scanning technology; the data can be used for remilling. Substandard milling caused by subsidence distress, such as block 4's substandard milling area, is as great as $5,898,600 \mathrm{~mm}^{2}$, accounting for $98.3 \%$ of the total areas. However, the substandard milling caused by rutting distress, such as block 1's substandard milling area, measures $215,050 \mathrm{~mm}^{2}$, accounting for $35.8 \%$ of the total area, and is located mainly on the wheel paths. The driving speed of the milling machine is also a potential factor affecting the milling results.

\section{Conclusions}

To address the shortcomings of the existing research for determining the locations of substandard milled area, a vehicular 3D laser detection system developed by Chang'an University was used to collect field asphalt milled surface texture data, a 3D model of the milled surface was constructed, and a texture depth and milling depth was proposed to analyze and evaluate the milling quality. The research results show that

(1) using the proposed laser scanning vehicular system, asphalt pavement milling surface information can be captured with high precision via high-density laser point data. The system can also be used to form a 3D milling surface model with transverse and longitudinal profiles at intervals of $0.5 \mathrm{~mm}$ to enable milling texture assessment and calculating the area of substandard milling;

(2) an improved method is proposed to evaluate the milled surface using 3D continuous transverse profiles. Using the milling surface texture model, the milling depth and texture depth of milling valley units can be calculated; these quantities are used to evaluate the roughness and texture of the milling surface. The preliminary results of the case study demonstrate the feasibility of the proposed method. The results show that the milling depth and texture 


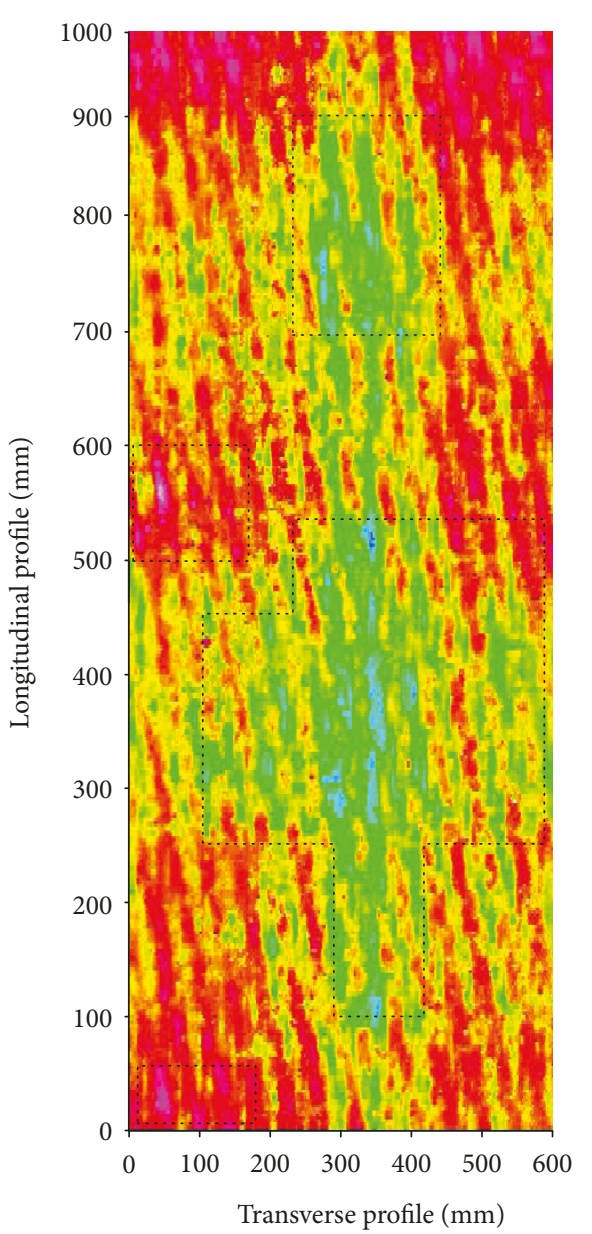

Block 2

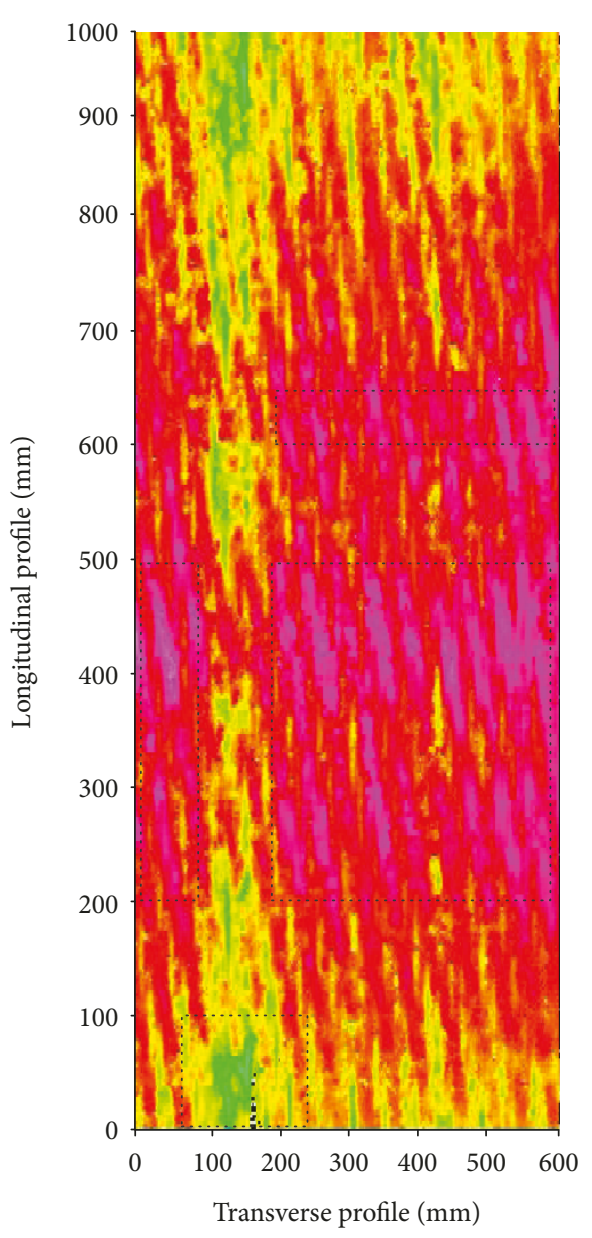

Block 3

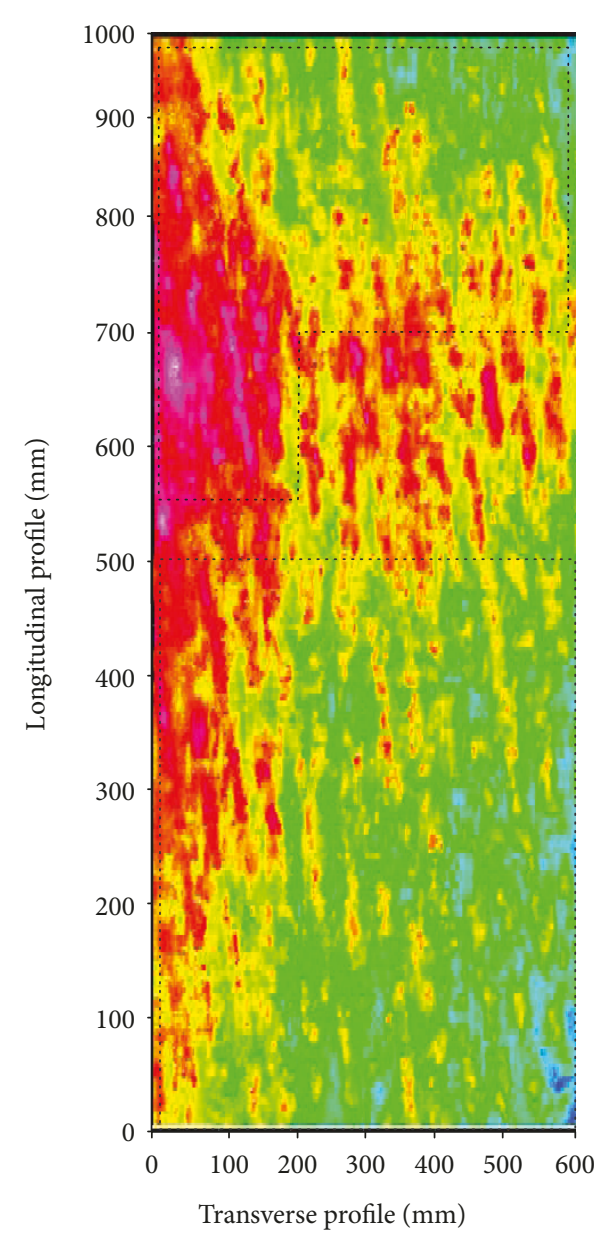

Block 4

Figure 10: Substandard sections of blocks.

TABLE 3: Substandard area and substandard milling percentage of blocks.

\begin{tabular}{lcccc}
\hline Block number & $\begin{array}{c}\text { Number of } \\
\text { substandard areas }\end{array}$ & $\begin{array}{c}\text { Max area of substandard } \\
\text { milling }\left(\mathrm{mm}^{2}\right)\end{array}$ & $\begin{array}{c}\text { Total substandard } \\
\text { area }\left(\mathrm{mm}^{2}\right)\end{array}$ & $\begin{array}{c}\text { Substandard milling } \\
\text { percentage }(\%)\end{array}$ \\
\hline Block 1 & 7 & 65,450 & 112,550 & 18.7 \\
Block 2 & 4 & 149,400 & 215,050 & 35.8 \\
Block 3 & 4 & 123,300 & 207,200 & 34.5 \\
Block 4 & 2 & 300,000 & $5,898,600$ & 98.3 \\
\hline
\end{tabular}

depth of milling valley units can be calculated precisely, and that the locations of substandard milling area can be delineated accurately, thereby improving the reliability of the milling surface assessment;

(3) the case study results demonstrate that the number, total amount, and percentage of substandard milling areas can be determined using the proposed method based on 3D laser scanning technology; such data can be used for remilling. Substandard milling caused by subsidence often influences a large area, whereas substandard milling caused by rutting distress is located mainly on wheel paths. The driving speed of the milling machine is also a potential factor affecting the milling results.

\section{Data Availability}

The raw/processed data required to reproduce these findings cannot be shared at this time due to legal or ethical reasons, and the data also forms part of an ongoing study.

\section{Conflicts of Interest}

The authors declare that they have no conflicts of interest. 


\section{Acknowledgments}

The work described in this paper was sponsored by the National Natural Science Foundation of China (no. 51508034), the Natural Science Foundation of Shaanxi Province (no. 2017JM5130), and the Transportation Technology Project of Inner Mongolia Autonomous Region (no. NJ-2015-31). Their support and assistance are gratefully acknowledged.

\section{References}

[1] Ministry of Transport of the People's Republic of China, X. M. Hong, D. L. Zhang, and H. L. Guo, Technical Specification of Maintenance for Highway (JTG H10-2009), Beijing, 2009.

[2] Ministry of Transport of the People's Republic of China, J. A. Shen, F. P. Li, and C. Jing, Technical Specification for Construction of Highway Asphalt Pavement (JTG F40-2004), Beijing, 2004.

[3] H. R. Gu, S. J. Jiao, C. Y. Xiao, F. C. Wang, and T. Lin, "Analysis and test on asphalt milling machine cutting load characteristic," China Journal of Highway and Transport, vol. 25, no. 3, pp. 154-158, 2012.

[4] L. I. Li, L. Sun, S. Tan, and G. Ning, "Line-structured light image processing procedure for pavement rut detection," Journal of Tongji University, vol. 41, no. 5, pp. 710-715, 2013.

[5] K. Z. Yan, Y. Jiang, L. K. Huang, and P. W. Hao, "Effect of bond condition on overlay performance," Journal of Hunan University, vol. 36, no. 5, pp. 11-15, 2009.

[6] L. Tashman, K. Nam, T. Papagiannakis, K. Willoughby, L. Pierce, and T. Baker, "Evaluation of construction practices that influence the bond strength at the interface between pavement layers," Journal of Performance of Constructed Facilities, vol. 22, no. 3, pp. 154-161, 2008.

[7] S. Y. Wang, "Influence factors of bond performance between asphalt surface layer and semi-rigid base," Journal of Traffic and Transportation Engineering, vol. 2, no. 4, pp. 13-15, 2010.

[8] L. Gao, A. de Fortier Smit, J. A. Prozzi, P. Buddhavarapu, M. Murphy, and L. Song, "Milled pavement texturing to optimize skid improvements," Construction and Building Materials, vol. 101, pp. 602-610, 2015.

[9] X. Hu and L. F. Walubita, "Effects of layer interfacial bonding conditions on the mechanistic responses in asphalt pavements," Journal of Transportation Engineering, vol. 137, no. 1, pp. 28-36, 2011.

[10] Liao Ning Province Quality and Technical Supervision Bureau, X. F. Nan, Y. Q. Liu, and X. H. Fan, Technology Specifications for Design and Construction of Ultra-Thin Friction Course (DB 21/T 1995-2012), Beijing, 2012.

[11] J. Laurent, D. Lefebvre, and E. Samson, “Development of a new 3D transverse laser profiling system for the automatic measurement of road cracks," in Symposium on Pavement Surface Characteristics, Portoroz Slovenia, 2008.

[12] K. H. McGhee, Automated Pavement Distress Collection Techniques: a Synthesis of Highway Practice. NCHRP Synthesis 334, Transportation Research Board, Washington, D.C, 2004.

[13] X. L. Zhou, N. D. Jiang, W. X. Xiao, M. P. Ran, and X. F. Xie, "Measurement method for mean texture depth of asphalt pavement based on laser vision," China Journal of Highway \& Transport, vol. 27, no. 3, pp. 11-16, 2014.
[14] P. A. Serigos, A. de Fortier Smit, and J. A. Prozzi, "Incorporating surface microtexture in the prediction of skid resistance of flexible pavements," Transportation Research Record: Journal of the Transportation Research Board, vol. 2457, no. 1, pp. 105-113, 2014.

[15] Y. (. J.). Tsai, Y. Wu, J. Lai, and G. Geary, "Ridge-to-valley depth measured with road profiler to control micromilled pavement textures for super-thin resurfacing on i-95," Transportation Research Record: Journal of the Transportation Research Board, vol. 2306, no. 1, pp. 144-150, 2012.

[16] X. Hao, Z. Sun, A. Sha, L. Wei, and H. Ju, "3D detection of the groove wear degree on cement concrete pavement," Chinese Journal of Scientific Instrument, vol. 36, no. 8, pp. 1767-1773, 2015.

[17] M. H. Lee, C. P. Chou, and K. H. Li, "Automatic measurement of runway grooving construction for pavement skid evaluation," Automation in Construction, vol. 18, no. 6, pp. 856863, 2009.

[18] L. Li, K. C. P. Wang, Q. J. Li, and W. Luo, “Automated runway groove measurement and evaluation," KSCE Journal of Civil Engineering, vol. 21, no. 3, pp. 758-765, 2017.

[19] Y. Tsai, Y. Wu, and Z. Lewis, "Full-lane coverage micromilling pavement-surface quality control using emerging 3D line laser imaging technology," Journal of Transportation Engineering, vol. 140, no. 2, 2014. 


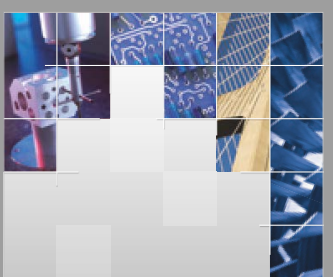

\section{Enfincering}
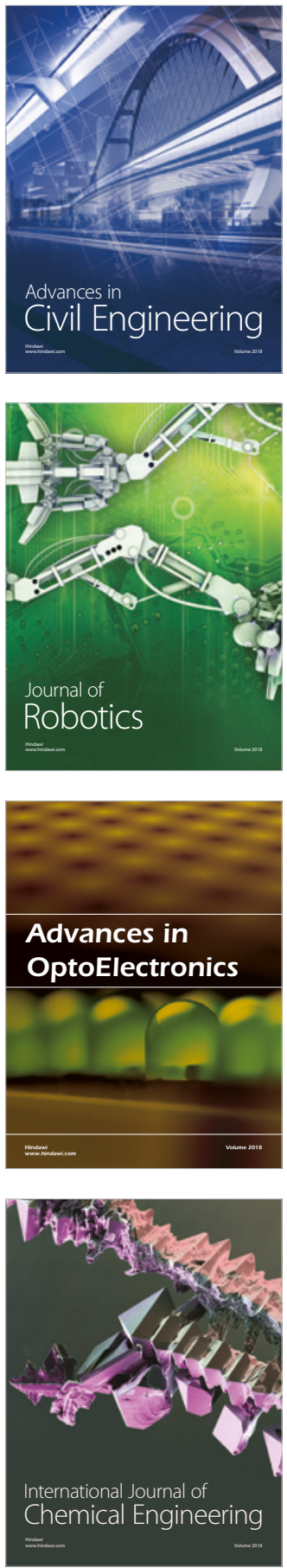

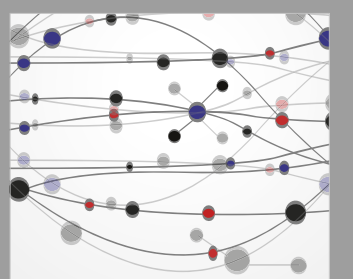

\section{Rotating \\ Machinery}

The Scientific World Journal

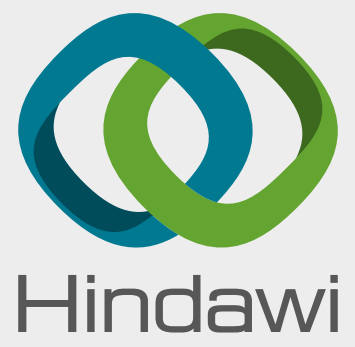

Submit your manuscripts at

www.hindawi.com
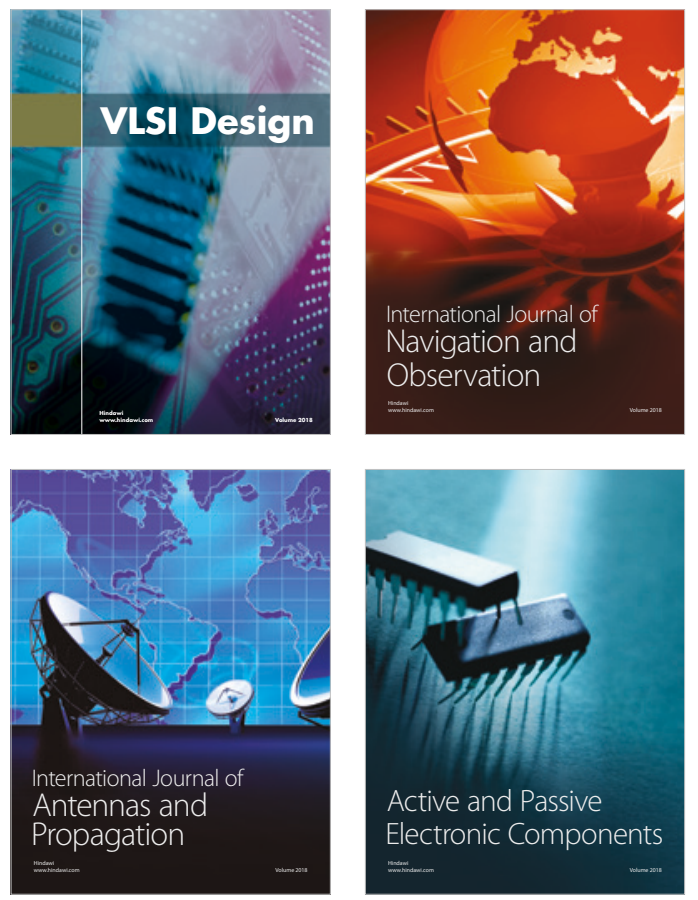
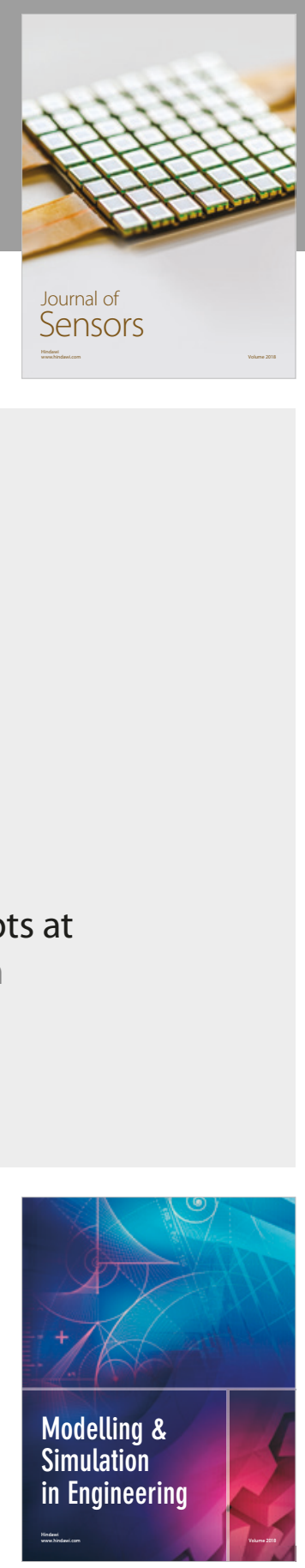

\section{Advances \\ Multimedia}
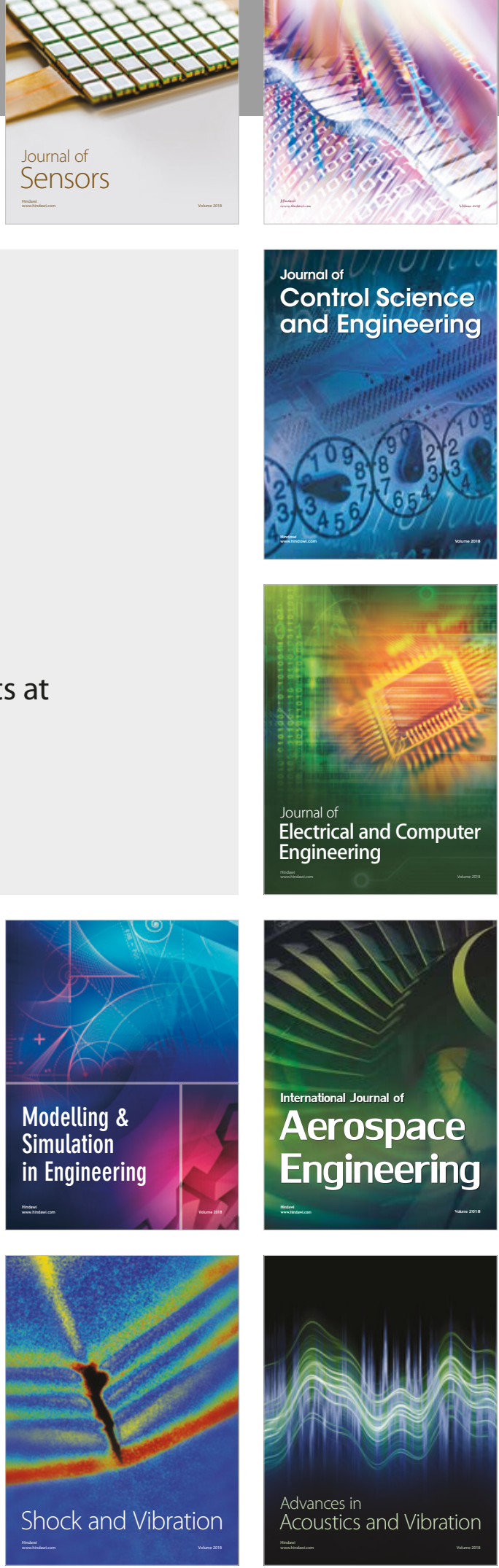